\title{
AS TRANSFORMAÇÕES SOCIOESPACIAIS DO TERRITÓRIO GOIANO NOS PERÍODOS DE 1930 E 1970
}

\author{
SOCIAL-SPATIAL TRANSFORMATIONS OF THE TERRITORY \\ OF GOIAS IN THE PERIODS OF 1930 AND 1970
}

\section{LAS TRANSFORMACIONES SOCIO-ESPACIALES DE LO TERRITORIO GOIANO EN LOS PERÍODOS DE 1930 Y 1970}

\author{
Denis Castilho \\ Doutorando pelo Programa de Pesquisa e Pós-Graduação em \\ Geografia do Instituto de Estudos Sócio-Ambientais da UFG \\ Campus Samambaia. Caixa Postal 131 / CEP: 74001-970, Goiânia - GO \\ E-mail: deniscastilho@hotmail.com
}

\begin{abstract}
Resumo
A transformação dos lugares pela reprodução ampliada do capital no território goiano envolveu, além dos meios de produção e da exploração do trabalho, as condições econômicas, políticas e culturais. Por conseguinte, alguns períodos foram emblemáticos no sentido dessas transformações, já que representaram esforços do Estado, de diferentes atores sociais, sobretudo, dos processos e ações subjugados às lógicas do capital internacional. Assim, o presente estudo propõe analisar o processo de modernização do território goiano a partir de dois períodos: de 1930 a 1970, que teve como expressão espacial a regionalização do Mato Grosso Goiano impulsionado pela criação de Goiânia e da Colônia Agrícola Nacional de Goiás - CANG, e o período que teve início a partir das décadas de 1960 e 1970, onde podemos mencionar a criação de Brasília e de programas como o Polocentro. Estes períodos, sobretudo o segundo, proporcionou a superação da população das cidades sobre a população residente no campo, principalmente nas porções Central e Sul de Goiás. Além de compreender este processo do ponto de vista histórico, é preciso compreender a sua expressão geográfica, neste caso, evidenciada pela forma como os processos e as ações se espacializam e/ou regionalizam.
\end{abstract}

Palavras-Chave: Território Goiano, modernização e transformações espaciais.

\begin{abstract}
The transformation of spaces from the extension reproduction of capital involved in the territory of Goiás, beyond the means of production and labor exploitation, economic, political and cultural conditions. Therefore, some periods were emblematic in the sense
\end{abstract}


of these transformations, as represented efforts of the State, social actors and hegemonic, especially the processes and actions subjugated to logics of international capital. Thus, this study proposes to examine the process of modernization of Goiás territory from two periods: from 1930 to 1970, that had as spatial expression the regionalization of Goiano's Mato Grosso, urged by the creation of Goiânia and the Agricultural National Colony of Goiás - CANG, and the period from 1960 and 1970, where we can mention the creation of Brasilia and programs like POLOCENTRO. This last period had as one of its spatial expressions the urbanization of Goias, found mainly in central and southern portions of this territory. In addition to understanding this process from a historical perspective, it is necessary understanding its geographical expression, in this case, evidenced by how the processes and actions get specialized and/or regionalized.

Keywords: Goiano territory, modernization and spatial transformations.

\section{Resumen}

La transformación de los lugares a traves de la reproducción extendida del capital en el territorio goiano involucra, más allá de los medios de producción y de la explotación del trabajo, las condiciones económicas, políticas y culturales. Así, algunos períodos fueron emblemáticos en el sentido de estas transformaciones, ya que fueron esfuerzos del Estado, de actores sociales, en especial, de los procesos y acciones sometidas a las lógicas del capital internacional. Así, este estudio propone examinar el proceso de modernización del territorio goiano a traves de dos períodos: 1930-1970, marcado por la regionalizacion del "Mato Grosso Goiano" (una región del Estado de Goiás-Brasil) impulsado por lá creación de Goiânia y de la Colonia Agrícola Nacional de Goiás CANG, y el período que se inició nos años de 1960 y 1970, donde se puede mencionar la creación de Brasilia y de programas como lo POLOCENTRO. Este período fue marcado por la urbanización de Goiás, que se encuentra, principalmente, en el partes del Centro y del Sur de este territorio. Además de comprender este proceso en la perspectiva histórica, hay que entender su expresión geográfica, en este caso, la manera cómo los procesos y las acciones constituyen por el espacio y/o región.

Palabras-Clave: Territorio Goiano, modernización y transformaciones espaciales.

\section{Introdução}

Compreender a espacialidade das ações imputadas no lugar é um passo primordial para entendermos o sentido da localização de determinadas relações sociais de produção no território Goiano. Para Bourdin (2001,p.41), "o passado pesa de maneira determinante sobre o presente". Uma formação socioespacial provém de processos: construção, reconstrução, dinamização e significação por diferentes grupos sociais. Por isso, o território é constituído por temporalidades diferenciadas. Ele é a condição substancial das relações sociais de produção e também um devir que se estabelece em 
movimento.

Ou seja, isso demonstra que compreender a instância espacial dos fenômenos é um passo primordial para entendermos o sentido da localização de determinadas relações sociais de produção. Nesse sentido, fundamentados em Moreira (1987), podemos dizer que o sentido dos territórios em movimento vem da história que se materializa em formas espaciais concretas.

Portanto, resta-nos "vasculhar" os tempos que estão no interior do espaço, pois são eles que nos possibilitarão compreender melhor a atual dinâmica socioespacial de Goiás a partir da nova divisão territorial do trabalho. Aqui nos é lançado um desafio: falar de processos, mas também compreendê-los em outras escalas. É por isso que nos é corrente falar de modernização do território goiano, já que ela, além de se constituir enquanto matriz espacial das transformações recentes (MENDONÇA, 2001), nos fornece os elementos necessários para compreender a forma como determinados elementos se espacializam. Isto é, se o espaço é um guardião de tempos, a sua compreensão passa pelo entendimento histórico de sua produção. No caso do território goiano também é assim: ele é produto da história da sociedade, e por isso, está em constante transformação.

Importante ressaltar que a análise de Goiás foi feita na proposta de identificar os elementos necessários que montam o quadro de sua formação territorial a partir da primeira metade do século XX. Não desconsiderando outros períodos da ocupação e/ou apropriação de Goiás, apresentamos dois dos quais são emblemáticos para a produção e transformação do quadro territorial de Goiás. O primeiro foi marcado pelas transformações do território goiano entre as décadas de 1930 e 1970 verificada no Mato Grosso Goiano e impulsionada pela criação de Goiânia e de projetos como a Colônia Agrícola Nacional de Goiás - CANG. O segundo, marcado pelas transformações a partir das décadas de 1960 e 1970, teve como exemplos a criação de Brasília e de programas como o Polocentro vindo a culminar com a superação da população das cidades sobre a população residente no campo. Em decorrência disso, podemos falar num período mais recente, que vem afirmar a continuidade das transformações deste território a partir de novas formas de apropriação: aumenta a intensidade dos conteúdos técnicos e virtuais assim como o poder da informação, mas também emerge, conforme Moreira (2006), o bioespaço. 
Conforme Chaveiro, Calaça e Rezende (2009), "para compreender a relação das mudanças demográficas com as transformações territoriais é necessário olhar Goiás em dois períodos: de 1930 até 1970 e outro a partir de 1970”. O primeiro é chamado pelos autores de antecipação da modernização conservadora, e o segundo (década de 1970), de limiar da modernização conservadora. E acrescentam:

O primeiro período se refere ao Goiás das políticas expansionistas (Construção de Goiânia, Marcha para Oeste, CANG, os Planos Rodoviários, etc.) que se delineia dos anos trinta até final de sessenta, do século XX. Esse período pode ser alcunhado de antecipação da modernização conservadora. Já o segundo período, principalmente após setenta, representa outro Goiás, amparado por uma infra-estrutura consolidada (rodovias, energia elétrica, comunicação) mas cindido (separação de Tocantins) ; um Goiás que sofre influência da construção de Brasília; um território com uma modernização conservadora que se articula à economia nacional e se prepara para, posteriormente, se aglutinar à economia internacional (CHAVEIRO, CALAÇA e REZENDE, 2009, p.18-19).

A expansão do modo de produção capitalista pelo território caracteriza o que chamamos de modernização. Ou seja, trata-se de um processo que envolve a transformação dos lugares no sentido da reprodução ampliada do capital e os conseqüentes impactos de amplitudes sociais e ambientais. E este processo envolve, além dos meios de produção e da exploração de trabalho, as condições econômicas, políticas e culturais. É por isso que alguns períodos são emblemáticos no sentido das transformações, já que representam esforços do Estado, de atores sociais e hegemônicos, sobretudo do capital internacional na constituição de um ambiente propício ao processo de expansão do capitalismo pelo território. No caso do território goiano trabalhamos, nesse artigo, os dois mencionados acima - de 1930 até 1970, que teve como expressão espacial a regionalização do Mato Grosso Goiano, e outro que teve início a partir de 1970. Vejamos.

\section{O processo de regionalização do Mato Grosso Goiano: o papel das frentes pioneiras}

Conforme Gomes; Teixeira Neto e Barbosa (2005), além de compreender uma grande área do território goiano (quase se confundindo com a atual Mesorregião Centro Goiano), o Mato Grosso Goiano é a região mais dinâmica, povoada e rica de Goiás. E 
acrescentam:

Ao utilizar o nome Mato Grosso Goiano para designar a região mais central de Goiás - atualmente desdobrada, com algumas modificações, em cinco microrregiões, o fizemos levando em conta tanto o seu caráter histórico (ela é assim chamada desde a chegada dos primeiros bandeirantes que descobriram Goiás) como a presença da grande floresta estacional decidual (floresta tropical) que a cobria originalmente [...] No século XX ela foi objeto de uma política de expansão da fronteira agrícola, demográfica e econômica adotada por Getúlio Vargas nos anos revolucionários de 30 - a Marcha para o Oeste (GOMES, TEIXEIRA NETO e BARBOSA, 2005, p. $125)$.

O Mato Grosso Goiano foi regionalizado a partir da expansão da reprodução do capital nacional em Goiás. As transformações que ocorreram a partir da década de 1930 deixam evidente que o foco daquele processo era montar uma estrutura no território goiano para a sua urbanização. Ou seja, a estratégia era trazer para essa Unidade da Federação as condições de reprodução do capital que ora se estabelecia no Brasil, principalmente com a indústria em São Paulo. Foi, portanto, que se verificaram no Mato Grosso Goiano fortes transformações nas formas de produção. Isso porque, até então havia o predomínio das frentes de expansão, que se caracterizavam pela busca de novas terras (matas) para a ocupação agrícola. Tratava-se de frentes que estavam sempre em movimento. As terras recém desmatadas garantiam fertilidade por um curto tempo. Com o "desgaste" do solo os agricultores migravam para novas áreas de matas. Conforme Martins (1997), essas frentes se localizavam numa zona intermediária entre a fronteira demográfica e a fronteira econômica. A chegada da fronteira econômica resultou no encontro da frente de expansão com a frente pioneira (MARTINS, 1997).

Foi o que ocorreu no Mato Grosso Goiano, especificamente no Vale do São Patrício. Como afirma SILVA (2004, p. 72),

A chegada da fronteira econômica, impulsionada pelos processos de modernização por intermédio da ferrovia anapolina, da abertura de estradas, da chegada de um grande número de camponeses em busca de tera e de novas forças econômicas interessadas nas possibilidades advindas com o desenvolvimento regional. Segue-se a isso uma valorização da região em termos econômicos. É esta a dinâmica da chegada da frente pioneira.

Esse período em Goiás foi impulsionado pela sobreposição das frentes pioneiras sobre as frentes de expansão. Enquanto essas últimas, naquele período, conviviam com 
o tradicional, com a agricultura familiar de subsistência e pelo deslocamento constante, as primeiras já traziam conteúdos da urbanização, da fixação, da produção e da ocupação racional do espaço. Ou seja, as frentes pioneiras trouxeram consigo os discursos da modernização, inclusive novos valores culturais advindos da expansão do capital reprodutivo.

As frentes pioneiras, segundo Martins (1997), convidam e induzem a modernização. No caso goiano, a entrada e fixação dessas frentes pelo Mato Grosso Goiano - estabelecendo vínculos dessa região com São Paulo, foi um processo importante para a sua modernização. Isso trouxe impactos para todas as instâncias espaciais, no entanto, ela ocorreu principalmente no campo. Isso significa que houve uma modificação nas formas de ocupação e de produção da terra, o que acarretou fortes impactos na produção agrícola do arroz e do milho, que seriam as principais culturas daquele momento.

Esse período da modernização ocorreu nas décadas de 1920 e 1930, mas também culminou com projetos como a criação de Goiânia na década de 1930 e da Colônia Agrícola Nacional de Goiás - CANG, na década de 1940. Antes disso, a ligação do território goiano com outras localidades teve papel primordial. Como é o caso da Estrada de Ferro no Sudeste Goiano, ligando às estações de Uberaba, Uberabinha e Araguari, que funcionavam como entreposto ao comércio goiano (BERTRAN, 1988). Conforme Arrais (2004) historicamente Goiás tem recebido pessoas de todo o Brasil, especialmente de Minas Gerais, da Bahia e do Maranhão, Estados que fazem fronteira com Goiás. Até 1930 as áreas mais populosas do Estado eram as de Catalão ao sul e de Tocantinópolis ao norte - hoje no Estado do Tocantins. Isso demonstra que as ocupações se davam pela migração de regiões fronteiriças, como de Minas Gerais ao sul e Maranhão e Bahia ao norte.

A partir de 1920 a dinâmica de ocupação teve novos rumos, principalmente pela interiorização da ferrovia. As ações provenientes do capitalismo emergente no oeste do país trouxeram resultados significativos. Em Goiás os trilhos avançaram por Goiandira (1912), Ipameri (1913), Pires do Rio (1922), Vianópolis (1921), Silvânia (1930) até alcançar Anápolis (1935), que se constituiu em importante centro cerealista, principalmente com o surto agrícola que veio a culminar, posteriormente, com a implantação da CANG (BERTRAN, 1988). Em 1910 a população de Anápolis era a 
décima nona do Estado, e em 1940 já era a segunda. Nesse período, essa cidade também adquiriu o perfil de principal centro regional do Estado.

A nova elite goiana, até então emergente, vendo a necessidade de infra-estrutura para a reprodução de seus domínios, permitiu a construção de estradas que ligassem à ferrovia, de modo que a expansão da produção avançasse por outras áreas do Estado, principalmente pelo Mato Grosso Goiano. A interiorização advinda do avanço da ferrovia até Anápolis e da abertura de estradas contribuíram para que novas formas de produção do capital se territorializassem no espaço goiano.

As fronteiras agrícolas favoreceram o aumento da produção de alimentos para atender a demanda da população urbana e, por outro lado, contribuiu para a reprodução do latifúndio e da agricultura tradicional no Centro-Oeste (BORGES, 2000, p.72).

Conforme França (1985), São Paulo teve influência direta nessa interiorização da modernização da agricultura em Goiás. Isso aconteceu com o objetivo de criar demanda para as indústrias paulistas, que produziam máquinas e insumos agrícolas. Naquele momento o papel do Brasil na economia mundial era de fornecer matéria prima, e São Paulo cumpria função substancial no fornecimento dos meios necessários para a interiorização da produção agrícola, que significava também o aumento da produção, a inserção do Brasil nos quadros da economia internacional e a ocupação pelo interior do país, que significava a integração da economia nacional. O próprio interior paulista era, naquele momento (e ainda é), um território onde a agricultura desempenha importante papel na dinâmica socioeconômica do território.

Ou seja, o Estado Brasileiro, naquele momento, capitalizou São Paulo para que ele fornecesse as condições de produção para o interior do país. Nesse sentido, conforme França (1985), o Mato Grosso Goiano foi a primeira região goiana a manter relações com São Paulo. Segundo Bertran (1988), Goiás estava sendo descoberto pelo mercado brasileiro ou mais propriamente o sudeste brasileiro "transformava Goiás em um anexo de seu sistema produtivo, aquele cinturão marginal em que o fator de produção mais convocado era a própria terra, de que Goiás era farto” (p.81). Borges (2000) também afirma que a expansão da fronteira agrícola em Goiás ocorreu em consonância com as transformações estruturais na economia do Sudeste do país.

Por traz disso havia uma política que veio criar as condições necessárias de reprodução do capital pelo país e assim, da expansão do domínio das classes 
dominantes daquele período. Havia, então, o esforço de acabar com as frentes de expansão, que representavam formas tradicionais de produção, impedindo, assim, as modernas formas que se emergiam. Tratavam-se das políticas de expansão da fronteira agrícola, demográfica e econômica que ocorreram nas décadas de 1930 e 1940, período revolucionário chamado de "Marcha para o Oeste", que teve como resultados imediatos a criação de Goiânia e da CANG (já citado anteriormente). Mas por que as políticas daquele momento se voltaram para a ocupação dos espaços ditos "vazios"?

O fato é que em meados da década de 1920, os povoamentos das frentes de expansão se apresentavam frágeis. E também, as principais áreas demográficas se localizavam na região servida pela estrada de ferro, na porção Sul do Estado, sendo, assim, restrita. Apesar da ferrovia já ter sido implantada até Anápolis na década de 1940, as classes dominantes se preocupavam com os espaços onde não mantinham seus domínios. Ou seja, a falta de ordenamento ou do domínio do território nacional era um problema a ser enfrentado. E Goiás era um dos Estados menos ocupados.

Portanto, o avanço das fronteiras demográficas e econômicas fazia parte da ideologia do Estado Novo, num período que também ficou conhecido como revolução de 1930. A proposta seria buscar a coincidência das fronteiras econômicas e políticas (DAYRELL, 1974). Além de voltar-se para a segurança nacional, o Estado estaria disposto a expandir o seu domínio, constituindo assim o seu território.

Essas políticas contribuíram com as ocupações do Mato Grosso Goiano atualmente Centro Goiano. Segundo Arrais (2004, p.73), “a colonização do governo federal colaborou com o fluxo de migrantes, especialmente para a CANG, no atual município de Ceres, no vale do Rio São Patrício, a partir da década de 1940”. Em 1950 a população rural do Estado representava 79,78\%, e a urbana apenas 20,22\%. Mas esse quadro passou por fortes alterações, já que em 1960 a população rural caiu para 69,93\%, e a urbana passou para 30,06\%. Entre 1970 e 1980 a população urbana já era maior que a rural, como mostra o gráfico 1 . 


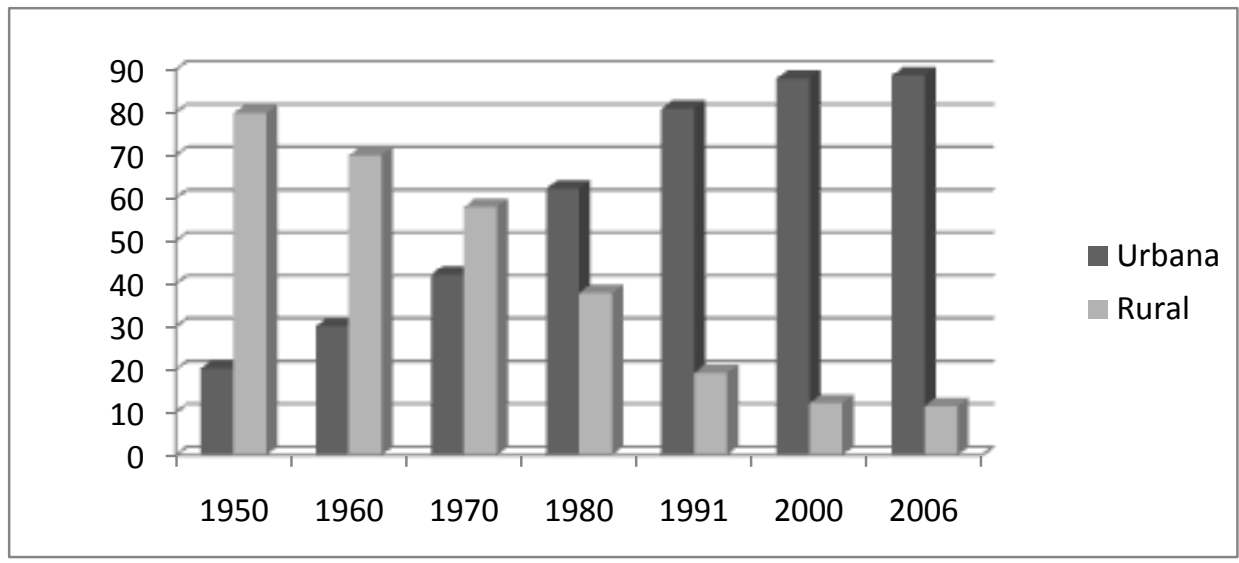

Gráfico 1 - Goiás: População Urbana e Rural (1950-1991).

Fonte: IBGE

A população até a década de 1970 era predominantemente rural. Por conseguinte, os programas de desenvolvimento foram decisivos para o crescimento populacional de Goiás que decorreu, sobretudo, da migração. Por exemplo, conforme Teixeira Neto (2002) já em 1940, $70 \%$ dos 826.414 mil habitantes eram migrantes. Na década de 1950 houve um crescimento de 4,65\% e a população ultrapassou um milhão de habitantes.

O aumento na população do Estado e as alterações nas formas de produção e das relações de trabalho foram impactos imediatos das políticas nacionais que, como já dissemos, representavam o esforço de integração política e econômica do território nacional, como também a inserção do Brasil na economia mundial, mas principalmente a reprodução das classes dominantes que se emergiam.

\section{A década de 1970 em Goiás e os novos conteúdos socioespaciais}

Apesar de falarmos de dois períodos da modernização - que significa dois períodos em que se alterou as relações de trabalho e as formas de produção, reconhecemos que o "primeiro" foi suporte para o "segundo", não estando, portanto, desligados um do outro. Também é certo que ambos os períodos (somados à outros anteriores) foram processos que transformaram Goiás de modo a inserí-lo nos quadros da economia nacional e internacional. Assim, podemos falar de "um único processo" que veio a criar as condições para a "globalização dos lugares goianos". No entanto, 
verificarmos que em cada período houve uma (re)funcionalização da dinâmica socioespacial de Goiás (alterando o sentido da diferenciação do território), o que nos faz considerar os dois períodos em suas relevâncias do ponto de vista das transformações espaciais.

Quando falamos do território goiano como um todo, reconhecemos que o período que marcou as décadas de 1960 e 1970 trouxe mais impactos que o período analisado no tópico anterior. Até porque as transformações nas décadas supracitadas (sobretudo na segunda) veio com um peso maior dos elementos da globalização.

Quando Santos \& Silveira (2001) menciona que a modernização encontra no território goiano um "vazio", isso do ponto de vista de não haver aqui uma resistência ao processo de modernização (o que foi diferente com o Nordeste brasileiro), na verdade eles deixaram de considerar que o capital encontrou as condições essenciais no Centro-Oeste para sua reprodução - como exemplo, podemos citar a proximidade (incluindo fatores logísticos) com o Sudeste brasileiro e o contexto histórico. Além do que, a estrutura social que se montou em Goiás acumulou condições primordiais para que, posteriormente, ocorresse a reprodução do capital moderno. Ou seja, dizer que a estrutura baseada no que Estevan (2004) chama de fazenda goiana - que passou por uma transformação nas décadas de 1930 e 1940 - não foi empecilho ou resistência para a entrada do capital moderno é um discurso insuficiente. Portanto, não se trata de resistência ou não, mas das condições encontradas e implantadas e dos interesses políticos e ideológicos diretamente relacionados às elites nacionais e regionais do período. Portanto, buscando fundamentos em Gramsci (1987), a explicação da entrada da modernização em diferentes territórios (no caso, em áreas goianas), está muito mais ligada a uma questão política e territorial do que simplesmente (ou somente) à resistência ou não da estrutura social que havia, antes, no lugar.

Se na década de 1930 houve a criação de Goiânia e mais adiante, na década de 1940, a criação da CANG, ambas provenientes das políticas de Getúlio Vargas, nas décadas de 1960 e 1970 houve a criação de infra-estruturas (como as rodovias federais) e de Brasília no governo de Juscelino Kubitschek. Se no primeiro período buscavam-se solos férteis - zonas de mata, no segundo a técnica e a ciência permitiram a inserção de novas áreas antes tidas como improdutivas. Isso porque, com as inovações, são os fatores técnico-sociais que vão determinar as especializações territoriais e não mais os 
fatores naturais (SANTOS e SILVEIRA, 2001). Portanto, no processo de modernização da agricultura, o Estado, através das políticas de financiamento (como o Polocentro) foi agente ativo no apontamento das localidades produtivas.

É por isso que até a década de 1960 o Centro-Oeste brasileiro tinha lavouras nos vales de rios, como foi o caso do "Vale do São Patrício", já que naquele período havia uma dependência maior aos fatores naturais. Mas nas décadas de 1960 e 1970, com a chegada do adubo químico, do trator, da colheitadeira, do silo forrageiro, de herbicidas e do calcário, novas áreas puderam ser representativas de altas produções agrícolas. Com isso, também foi introduzido um calendário agrícola com alternância de agriculturas de modo a racionalizar a produção (SANTOS e SILVEIRA, 2001).

A EMBRAPA teve papel substancial na década de 1970, já que representou a possibilidade de atingir novas áreas para plantio. Descobriu-se que através de correções (adição de calcário e insumos agrícolas) extensas áreas do Cerrado, antes improdutivas, poderiam se constituir em um seleiro agrícola. De acordo com Santos e Silveira (2001), o Sudoeste Goiano foi apropriado pelas técnicas e financiamentos para o cultivo de algodão, soja, milho e arroz, caracterizando um verdadeiro receptáculo das agriculturas "expulsas" do Sudeste brasileiro.

Isso trouxe um novo significado para o campo goiano, pois até meados das décadas de 1960 e 1970 a economia deste território era sustentada basicamente por dinâmicas agropecuárias ainda tradicionais - como é o exemplo da pecuária extensiva e da agricultura camponesa, ou seja, a cidade ainda não cumpria papel substancial do que se fazia no meio rural. Mas em decorrência da modernização agrícola, já na década de 1960, Goiás registrava um forte crescimento urbano proveniente do que se chamava de êxodo rural (GOMES; TEIXEIRA NETO e BARBOSA, 2005). A forte migração campo-cidade culminou, nas décadas de 1970 e 1980, com a superação da população das cidades sobre a população residente no campo. Segundo Deus (2002, p. 190),

As migrações campo-cidade favoreceram um forte processo de urbanização. Esse processo ocorreu em todo o país, porém foi mais intenso no CentroOeste, que será a segunda região mais urbanizada da Federação em 1980, com apenas 32,21\% da população morando na zona rural.

Conforme a Secretaria de Estado do Planejamento e Desenvolvimento SEPLAN (2007), Goiás, no período entre as décadas de 1950 e 1970 teve altas taxas de 
crescimento anual (4,65 e 4,4, respectivamente). As antigas estruturas agrárias foram se dissolvendo e levando grande parte dos camponeses a afluírem para as cidades. Os incentivos estatais para a modernização da agricultura trouxeram mudanças na base econômica primária e o Cerrado (principalmente as áreas planas da porção sul do Estado) passou a ser sinônimo de produtividade. E ainda, os investimentos estatais em infra-estrutura proporcionaram grande crescimento econômico nos anos 1970 e 1980. Conforme Deus (2002), a mecanização da produção deu impulso ao processo de inserção de Goiás na economia nacional e internacional. Aqui, a modernização, através da técnica, da ciência e da informação (Santos, 1996) mostrou-se transformadora, e a década de 1980 foi representativa dessas transformações.

Nesse período a população alcançou 3.120 .718 habitantes. O ano de 1991 registrou um total de 4.018.903 habitantes e o ano de 2000 atingiu 5.003.228 de habitantes. Em 2007 também foi registrado um crescimento, já que a população alcançou a quantidade de 5.647.035 habitantes. Entre as décadas de 1980 e 1991 a taxa de crescimento de Goiás (2,33\%) foi maior que a nacional (1,93\%). O mesmo ocorreu nos anos seguintes (tabela 1).

Tabela 1 - Taxa média geométrica de crescimento anual Goiás, Centro-Oeste e Brasil - 1970-2007

\begin{tabular}{|c|c|c|c|}
\hline \multirow{2}{*}{} & \multicolumn{3}{|c|}{ Taxa média geométrica de crescimento anual (\%) } \\
\cline { 2 - 4 } & Goiás & Centro-Oeste & Brasil \\
\hline $1970 / 1980$ & 2,77 & 4,05 & 2,48 \\
\hline $1980 / 1991$ & 2,33 & 3,01 & 1,93 \\
\hline $1991 / 1996$ & 2,36 & 2,18 & 1,36 \\
\hline $1996 / 2000$ & 2,60 & 2,60 & 1,97 \\
\hline $1996 / 2007$ & 2,05 & 2,12 & 1,44 \\
\hline $2000 / 2007$ & 1,74 & 1,84 & 1,15 \\
\hline
\end{tabular}

Fonte: IBGE

Como apresenta o gráfico 1 do tópico anterior, a taxa de urbanização teve um forte crescimento a partir da década de 1980. Em 1991 ela foi de 80,82\% e em 2006 atingiu $88,57 \%$ (tabela 2 ). 
Tabela 2 - População, situação do domicílio, taxa de urbanização e densidade demográfica - GOIÁS, 1991, 2000 e 2006

\begin{tabular}{|c|c|c|c|c|c|}
\hline \multirow{2}{*}{} & & \multicolumn{2}{|c|}{ Situação do domicílio } & & \\
\cline { 3 - 4 } & & Urbana & Rural & & \\
\hline $1991(1)$ & 4.019 & 3.248 & 771 & 80,82 & 11,82 \\
\hline $2000(1)$ & 5.003 & 4.397 & 607 & 87,89 & 14,71 \\
\hline $2006(2)$ & 5.750 & 5.093 & 657 & 88,57 & 16,91 \\
\hline
\end{tabular}

Fonte: IBGE (1) Censo (2) PNAD

O crescimento da população total teve forte participação da migração interestadual. De acordo com o PNAD (2001), na década de 1990, 29\% dos residentes em Goiás eram originários de outras Unidades da Federação, destacando os mineiros $(7,6 \%)$, baianos $(4,7 \%)$, brasilienses $(3,1 \%)$, tocantinenses $(1,8 \%)$, maranhenses $(1,7 \%)$ e paulistas $(1,6 \%)$. Nos anos posteriores houveram novos fluxos migratórios para Goiás. Em 2000 o quadro de migrantes apontava, novamente, os mineiros $(6,62 \%)$ e baianos $(3,77 \%)$ com maiores percentuais (SILVA, 2005).

Os dados apresentam uma significativa mudança no perfil demográfico de Goiás. A consolidação deste território como moderna área de produção agroindustrial foi verificado "após as alterações promovidas na sua base econômica com espetacular modernização da produção agropecuária" (DEUS, 2002, p. 177). Não podemos deixar de frisar a importância da logística que foi montada nesse território, como é o caso das rodovias, que desempenharam (e desempenham) papéis fundamentais nas redes urbanas e na consolidação da dinâmica territorial.

Importante ressaltar que o conteúdo dessas transformações não se incorporou de maneira igual por todo o território goiano. Isso porque, pelos programas de financiamento e pelas condições de reprodução do capital, a modernização não atingiu as áreas de maneira homogênea, constituindo uma "modernização em manchas" (SANTOS \& SILVEIRA, 2001). Isso também ocorreu em Goiás. Como reflexo desse crescimento desigual, a taxa de crescimento da população por microrregião entre 1970 e 2000 é um demonstrativo desse contraste. De acordo com o Instituto Brasileiro de Geografia e Estatística - IBGE (2000), entre 1970 e 2000, as Microrregiões do Entorno de Brasília e de Goiânia apresentaram as maiores taxas de crescimento, com 402,10\% e $256,56 \%$ de crescimento, respectivamente, o que se explica pelo crescimento das regiões metropolitanas de Goiânia e de Brasília. Já as Microrregiões de Ceres (-4,09\%), 
Iporá (-9,73\%) e Anicuns (-4,07\%) apresentaram as menores taxas. Chaveiro, Calaça e Rezende (2009) afirmam que essa diferenciação se intensificou com o desenvolvimento do capitalismo no território goiano, já que este processo fortaleceu o desenvolvimento desigual e combinado.

Conforme Peliano (1990), as migrações não são apenas fluxos e sentidos dos deslocamentos populacionais ou sequer resultado de aparentes fatores determinantes, mas fundamentalmente distribuição espacial da força de trabalho. Rodrigues (2007) afirma que as migrações são produtos do capitalismo enquanto representam deslocamentos de trabalhadores necessários à absorção produtiva pelo sistema, ou enquanto representem deslocamentos de trabalhadores excedentes a engrossarem a superpopulação relativa. Portanto, a distribuição de migrantes pelo território goiano acompanha as regiões onde há maior produção e circulação de capital. A população não natural no ano de 2000 se concentrava principalmente nas regiões onde o crescimento econômico foi maior: Região Metropolitana de Goiânia, no Entorno de Brasília e no Sudoeste Goiano.

As transformações socioespaciais que ocorreram a partir das décadas de 1960 e 1970 foi verificado principalmente na parte central e sul do Estado. Segundo Estevan (2000) a porção Norte do Estado permaneceu com um desenvolvimento econômico baixo. Mesmo nessa região há disparidades entre as microrregiões de Porangatu, São Miguel do Araguáia, Chapada dos Veadeiros e Vão do Paranã. Entre elas a microrregião de Porangatu sempre foi beneficiada pela BR-153 (Belém-Brasília), pela posição de cidades como Uruaçu e Porangatu e pela localização de indústrias mineradoras em Niquelândia e Minaçu. Essas cidades e a logística propiciada pela rodovia deixam essa região com conteúdos diferentes dos dois extremos (Nordeste e Noroeste goianos). O primeiro tem alta produção agropecuária, principalmente gado bovino em Mozarlândia, Nova Crixás e São Miguel do Araguáia e o ouro em Crixás. Por conseguinte, é o Nordeste Goiano que aparece como a região com menor crescimento econômico. O que se explica pelo processo histórico de sua ocupação (BARREIRA, 2002), pelas condições geomorfológicas, sobretudo pela ausência de infra-estrutura e da logística e pelos elementos político-ideológicos que se estabeleceram naquela porção do Estado. Estamos mencionando as microrregiões da porção Norte do território goiano para dizer que há nelas conteúdos da modernização bastante distintos daquela verificada nas 
porções Central e Sul do Estado (aqui analisadas nos dois períodos), o que confere fundamento socioespacial do processo de modernização do território goiano.

Portanto, as formas como as transformações se manifestam temporalmente só faz sentido a partir da maneira como se manifestam espacialmente. As transformações desencadeadas a partir das décadas de 1960 e 1970 evidenciaram seus vínculos históricos, as vontades políticas de seus atores, a incorporação das lógicas externas, a tendência do movimento de mundialização dos lugares, sobretudo, a forma como esses elementos se espacializam e o modo como se constituem pelas relações sociais de produção.

\section{Considerações finais}

As transformações verificadas nos dois períodos aqui analisados foram emblemáticas no sentido das configurações espaciais, como exemplo da modernização agrícola verificada no Mato Grosso Goiano a partir da década de 1930 e das alterações socioespaciais verificadas nas porções Sul e Central do território goiano a partir das décadas de 1960 e 1970. Além da maneira desigual da distribuição econômica e demográfica, a modernização do território, apesar de evidenciar a urbanização, não extinguiu os traços rurais. Em Goiás, a relação entre o urbano e o rural não desapareceu, pelo contrário, intensificou-se.

É por isso que Chaveiro (2004) ao discutir o processo da urbanização de Goiás, ou em seus termos "urbanização do sertão", afirma que "a lógica de uma economia baseada na agropecuária sedimentou uma tipologia de urbanização em Goiás” (p. 100). Como resultado, podemos exemplificar a grande relação que as cidades goianas mantêm com o campo. Isto é, apesar de ser uma relação diferente daquela onde as estruturas agrárias desempenhavam papéis hegemônicos, as relações das cidades goianas com o campo se intensificaram. Só que agora a supremacia é do urbano e/ou das lógicas distantes.

Por conseguinte, esse tipo de relação, fruto dos processos de modernização do território, proporcionou a dispersão da informação e do consumo pelo território, inclusive nas mais "distantes" localidades, verificando-se, sobretudo, o aumento 
intensivo das populações vivendo em cidades. Esses dados indicam que as transformações territoriais, sobretudo a partir da década de 1970, vieram reforçadas pelo que Santos (1994) chama de meio técnico-científico-informacional, culminando com a globalização dos lugares e com a alteração do conteúdo socioespacial de cada localidade. Este estudo foi desenvolvido no sentido de compreender este processo do ponto de vista espacial considerando, também, a sua dimensão histórica.

Com isso, esperamos que as reflexões aqui desenvolvidas contribuam com o debate sobre as transformações do território goiano pela via da análise da sociedade a partir de sua espacialidade ou pelo que Gomes (2009) chama de ordem espacial. Ou seja, as ações e os processos se localizam. Mas essa localização é relacional e permite, a partir de um estudo que demanda esforço, dedicação e muito trabalho de reflexão, identificar um sentido espacial coerente e explicativo, o qual representa uma importante dimensão dos processos e das ações que dinamizam o território.

\section{Referências Bibliográficas}

ARRAIS, T. P. A. Geografia Contemporânea de Goiás. Goiânia: Vieira, 2004.

BARREIRA, C. C. M. A. Vão do Paraná: a estruturação de uma região. Brasília: Ministério da Integração: Universidade Federal de Goiás, 2002.

BERTRAN, P. Uma Introdução à História econômica do Centro-Oeste do Brasil. Brasília: CODEPLAN, Goiás: UCG, 1988.

BORGES, B. G. Goiás nos quadros da economia nacional: 1930-1960. Goiânia: UFG, 2000.

BOURDIN, A. A questão local. (trad.: Orlando dos Reis). Rio de Janeiro: DP\&A, 2001.

BRASIL. Censo demográfico: 2007. Brasília: IBGE, 2008. 
CHAVEIRO, E. F. A urbanização do sertão goiano e a criação de Goiânia. In: GOMES,

H. (Org.). O Espaço Goiano: Abordagens Geográficas. Goiânia: Associação dos Geógrafos Brasileiros, 2004.

CHAVEIRO, E. F; CALAÇA, M; REZENDE, M. C. da S. A Dinâmica Demográfica de Goiás. Goiânia: Ellos, 2009.

DAYRELL, E. G. Colônia Agrícola Nacional de Goiás: análise de uma política de colonização. Dissertação de Mestrado (Instituto de Ciências Humanas e Letras da UFG). Goiânia: Universidade Federal de Goiás, 1974.

DEUS, J. B. de. As atuais transformações estruturais na economia goiana e os seus desdobramentos nas mudanças socioespaciais. In: ALMEIDA, Maria Geralda de (Org.) Abordagens geográficas de Goiás: o natural e o social na contemporaneidade. Goiânia: IESA, 2002. p. 177-196.

ESTEVAM, L. O Tempo da Transformação: estrutura e dinâmica da formação econômica de Goiás. (2 ${ }^{\mathrm{a}}$ ed). Goiânia: UCG, 2004.

FRANÇA, M. de S. Terra, Trabalho e História: a Expansão Agrícola no "Mato Grosso" de Goiás - 1930/1955. Tese de Doutorado (mimeografado). São Paulo: USP, 1985.

GOMES, H; TEIXEIRA NETO, A; BARBOSA, A. S. Geografia: Goiás / Tocantins. 2. ed. rev. e ampl. Goiânia: UFG, 2005.

GOMES, P. C. da. Um lugar para a Geografia: contra o simples, o banal e o doutrinário. In: MENDONÇA, F. et al. Espaço e Tempo: complexidade e desafios do pensar e do fazer geográfico. Curitiba: DEMADAN, 2009.

GRAMSCI, A. A questão Meridional. (Seleção e introdução: Franco de Felice e Valentino Parlato; Tradução: Carlos Nelson Coutinho e Marco Aurélio Nogueira. Rio 
de Janeiro: Paz e Terra, 1987.

MARTINS, J. De S. Fronteira: a degradação do outro nos confins do humano. São Paulo: Hucitec, 1997.

MENDONÇA, M. R. A urdidura espacial do capital e do trabalho no Cerrado do Sudeste Goiano. Dissertação (Doutorado em Geografia) - Universidade Estadual Paulista Júlio de Mesquita Filho, UNESP. Presidente Prudente, 2001.

MOREIRA, R. O discurso do avesso. Rio de Janeiro: Dois Pontos, 1987.

Para onde vai o pensamento geográfico? Rio de Janeiro: Contexto, 2006.

PELIANO, J. C. Acumulação de Trabalho e Mobilidade do Capital. Brasília: UnB, 1990.

RODRIGUES, U. B. Dilemas do trabalho no mundo contemporâneo: Migração Internacional dos Goianos (Mestrado em Geografia). Instituto de Estudos SócioAmbientais (IESA), Universidade Federal de Goiás (UFG), Goiânia, 2007.

SANTOS, M. Técnica, espaço e tempo: glogalização e meio técnico-científico informacional. São Paulo: Hucitec, 1994.

A Natureza do Espaço: técnica e tempo, razão e emoção. São Paulo: Hucitec, 1996.

SANTOS, M. \& SILVEIRA, M. L. O BRASIL: território e sociedade no início do século XXI. Rio de Janeiro: Record, 2001.

SECRETARIA DE ESTADO DO PLANEJAMENTO E DESENVOLVIMENTO. Anuário Estatístico do Estado de Goiás - 2000. Goiânia: SEPLAN, 2000. 
Anuário Estatístico do Estado de Goiás - 2003. Goiânia: SEPLAN, 2003.

Anuário Estatístico de Goiás - 2007. Goiânia: SEPLAN, 2007.

SILVA, M. C. da. A dinâmica demográfica de Goiás. Dissertação (Mestrado em Geografia). Instituto de Estudos Sócio-Ambientais (IESA), Universidade Federal de Goiás (UFG), Goiânia, 2005.

SILVA, S. D. Um outro olhar sobre o lugar: a Cang no tempo da fronteira. Sociedade e Cultura. V.5, n. 1 (jan/jun.2002). Goiânia: Departamento de Ciências Sociais, FCHF/UFG, 2004.

TEIXEIRA NETO, A. O Território Goiano: formação e processo de povoamento e urbanização. In: ALMEIDA, Maria Geralda de (Org.) Abordagens geográficas de Goiás: o natural e o social na contemporaneidade. Goiânia: IESA, 2002. p.11-46.

Recebido para publicação em maio de 2010 Aprovado para publicação em junho de 2010 